\title{
Teachers' Assessment of Inattentive Classroom Behavior Among Primary School Students in Ilorin City, Kwara State, Nigeria
}

\author{
Samuel Kolawole Ajiboye ${ }^{\bowtie 1}$, David Obafemi Adebayo', Saidu Abubakar² \\ 1 Department of Counsellor Education, Faculty of Education, University of llorin \\ 2 Department of Arts Education, Faculty of Education, University of Ilorin \\ $\bowtie$ ajiboye.sk@unilorin.edu.ng
}

\begin{abstract}
Inattentive behavior could become unnoticed but it is often a major constraint to effective classroom instruction and students' performance. This research investigated teachers' assessment of inattentive classroom behavior among primary school students in Ilorin city, Kwara State, Nigeria. The research is a survey research with the population consisted of 1,568 teachers, while 160 participants were purposively selected. A questionnaire type of instrument was used in the research. The results showed a reliability coefficient of $r=0.81$ after conducting the test-retest reliability. The research question was analyzed with descriptive statistics while the hypotheses were tested with t-test and ANOVA at the 0.05 level of significance. Inattentive classroom behavior was high among primary school students as assessed by teachers. Teachers' assessment of students' inattentive behavior was similarly based on gender and qualification but different based on work experience. It was recommended that early childhood education/primary school teachers and counselors as well as other stakeholders in primary education should synergize to mitigate the high level of inattentive classroom behavior among students in order to enhance teaching-learning.
\end{abstract}

Keywords: inattentive behavior, students, primary school, classroom

How to Cite: Ajiboye, S., Adebayo, D., \& Abubakar, S. (2020). Teachers' Assessment of Inattentive Classroom Behavior Among Primary School Students in llorin City, Kwara State, Nigeria. Mimbar Sekolah Dasar, 7(2), 172-183. doi:https://doi.org/10.17509/mimbar-sd.v7i2.24101

INTRODUCTION In the school rules and instructional practice, students' attentiveness in the classroom could be related to the key operational construct of active learning time or its equivalents, which include duration on an activity, active learning time, or endurance. Thus, attentiveness is believed to be a major determinant of academic success of school children. However, inattention, which often comes with its attendant consequence, has become a notorious phenomenon that manifests among school children of lower ages. Inattention refers to a situation of reduced concentration span of mental powers upon an object or activity. I a global view, everyone is sometimes inattentive but, as a behaviour, the act is often associated with children particularly in the classroom learning environment. Inattentive impulsiveness includes being impatient, not waiting for one's turn, making quick decisions without thinking about the consequences, and blurting out things without thinking. Students with inattention behaviour typically have trouble getting organized, staying focused, participating in classwork, getting along with teachers and peers, coping with classroom 
demands, and getting good grades in an academic exercise. Such children may be fidgety, noisy, and unable to adapt to changing situations.

Inattentive behaviour is one of the features of Attention Deficit Disorder, a neurological condition that involves problems that are peculiar to children particularly while receiving classroom instruction. Some children with inattentive behaviour may exhibit traits that are explorative, inquisitive, playful, restless, impulsive, and overactive than others (Smith et al., 2019). Students with attention problems would lack self-control. and they are sometimes at the centre of conflict just to create scene and excitement (Uwe, 2000). When left unchecked, the students might become hindrances to themselves, their schoolmates, and teachers in school, thereby creating a counter-productive environment for the achievement of the objectives of the basic education as may be formulated by the policymakers.

In Nigeria, basic school is the first stage that spans through the lower and upper categories of early childhood education. Like the foundation, the stage is very important because of its relevance to the success of the other higher levels (Secondary and Higher/Tertiary). The objectives of basic education, inter alia, are to inculcate permanent literacy, numeracy and ability to communicate effectively; lay a sound basis for scientific, critical and reflective thinking; promote patriotism, fairness, understanding and national unity; instill social, moral norms and values in the child; develop in the child the ability to adapt to the changing environment; and provide opportunities for the child to develop life manipulative skills that will enable the child function efficiently in the society within the limit of the child's capacity (NERDC, 2013). These objectives are designed for the total development of the three (cognitive, affective, and psychomotor) domains of the child within a space of nine years because basic education is designed for children between 5 and 14 years old; the period when the manifestation of inattentive behavior could be at its peak. Therefore, the teachers are saddled with the responsibility of identifying various behaviour deficits that could hamper adequate learning. Thus, as persons who act in loco parentis, they are expected to establish a close relationship, which could help them notice levels of inattention among basic school students in the classroom in order to remove learning barriers.

Students with attention-deficit would experience difficulty in achieving the expectations of the general education curriculum (Smith et al., 2019). This may be influenced by their inattentive impulsive tendencies. If inattention is identified early enough or not treated, these students are at great risk of experiencing learning difficulties, poor self-esteem, interpersonal challenges, and dropping out of school. The symptoms of students' inattentive behaviour include missing details and becoming distracted easily, having trouble focusing on the task at hand, becoming bored quickly, having difficulty in learning or organizing new information, having difficulty in completing homework, losing items needed to stay on task, and becoming confused easily or daydreaming frequently. Attention deficit is one of the most 
commonly diagnosed behavioural problems in the U.S. classroom, particularly among elementary (basic) school children (Handelman, 2011). Similarly, teachers rated high attention deficits among primary school students compared with older upper-grade students in the US (Willcutt, 2012).

Inattentive behaviour is often irritable because of the adverse effect on pupils' performance and the efforts of teachers and parents. Attentive behaviours are directly related to learning outcomes (Smith et al., 2019; Stöppler, 2010). The studies suggested that attentiveness is an important variable associated with students' behaviour at school, through which the effect of learning experiences is mediated to influence learning outcomes. Children with inattentive behaviour are more likely to show the following characteristics in a way that disrupts classroom activities: an apparent inability to pay close attention to a task or a tendency to make careless mistakes, difficulties in focusing on activities or tasks and giving the impression of not listening while other people are talking (Nall, 2018). Other features include experiencing difficulty with time management and task organization, losing items or accessories necessary for daily function frequently, becoming distracted easily, forgetting to complete tasks and fulfil obligations, avoiding tasks that require prolonged focus and thought, and finding it difficult to play or engage in activities without creating excessive noise, difficulties with following instructions to complete tasks.

Children occasionally have difficulty sitting still or sustaining attention, however, for some children, the problem could be significantly persistent and serious in which it interferes with learning and relationships. Most children are challenged by problems related to inattention while a cluster of these problems could be defined as hallmark symptoms of ADHD (Rodriguez, 2017). The study found that one out of six basic school students in England showed inattentive behavior; around one in six young children showed relatively mild inattentive behavior. Furthermore, the findings showed that children who have mild attention problems at the age of five are, on average, around three months behind their peers by the time they reach the end of basic school (Merrell, 2017). Although some children may not have ADHD, which could make them go unnoticed, yet they are at risk of falling behind academically. In most cases, mild inattention can be difficult to spot in the classroom because of its trivial features. The types of behaviors associated with mild inattentive behavior include losing attention during lessons, failing to listen, and various other related behaviors. Regardless of work experience, marital status, educational level, and gender, there are similarities among teachers in their reports of inattentive behavior among students (Lundervold et al., 2017). In a related study, teachers found the similarity in their expression of attention deficit hyperactivity disorder among school children in Port-Harcourt, Nigeria (Alikor et al., 2015). Further, respondents reported attention deficit was significantly prevalent among students . 
Students with inattentive behavior are easily distracted, often seem to be daydreaming, and they do not finish what they start and repeatedly make what appear to be careless mistakes (Stöppler, 2010). Some children often exhibit traits that are explorative, inquisitive, playful, restless, and impulsive and overactive than others as features of inattentive behavior. Therefore, the research examined teachers' assessment of inattentive classroom behavior among primary school students in llorin city, Kwara State, Nigeria. In addition, the moderating variables of gender, educational qualification, and work experience were considered to determine their influence on the responses of the participants.

\section{Problem Statement}

Inattentive behavior is a major debilitating phenomenon that not only hampers the students' progress but also the efforts of the teachers in ensuring quality classroom instruction. Inattentiveness. Students who showed inattentiveness during childhood are associated with worse academic achievements up to 10 years later in life (Rodriguez, 2017). In addition, basic school students with high inattentive behavior performed worse in school (Lundervold et al., 2017). Inattentive behavior is a problem that is often invisible and ingrained in themselves, which is often described as sloppiness, laziness, and even stubbornness (Stöppler, 2010). Regardless of the number of students with inattentive behavior, or the level at which the behavior, is exhibited, they are frequently noticed by the classroom teachers because of the enormity of the consequences. Students with attention-deficit tended to repeat class, achieve lower grades, and process information slower than their peers (Adesola \& Asifatu, 2013). Based on the study on knowledge and attitudes towards Attention Deficit Hyperactivity Disorder (ADHD) among primary school teachers in Lagos State, Nigeria, it revealed inadequacy in teachers' knowledge of ADHD among basic school students (Jimoh, 2014). Furthermore, gender, religion, qualification and age did not influence the response of the participants. Moreover, high incidence of attention deficit among primary school students can be based on years of experience and the number of children (Egbochuku \& Abikwi, 2007). In order to substantiate the earlier studies and fill the gaps in research, the research investigated teachers' assessment of inattentive classroom behavior among primary school students in Ilorin city, Kwara State, Nigeria.

This research also proposed a question, namely what is the level of inattentive classroom behavior among primary school students as assessed by teachers in llorin city, Kwara State, Nigeria?

The research hypotheses are:

1. There is no significant difference in teachers' assessment of inattentive classroom behaviour among primary school students in Ilorin city, Kwara State, Nigeria based on gender. 
2. There is no significant difference in Teachers' assessment of inattentive classroom behaviour among primary school students in Ilorin city, Kwara State, Nigeria based on qualification

3. There is no significant difference in Teachers' assessment of inattentive classroom behaviour among primary school students in llorin city, Kwara State, Nigeria based on work experience

\section{METHOD}

\section{Research Design}

This research employed a descriptive survey method. A survey involves interviews, use of questionnaires or discussions with larger audiences that represent the entire population of the study, and are often conducted on more specific topics (Gutcheck, 2020). Since this research sought to use questionnaires on a specified sample of the population, the method was considered appropriate to investigate teachers' assessment of inattentive classroom behavior among primary school students in Ilorin city, Kwara State, Nigeria.

\section{Population, Sample, and Sampling}

The population for this study consisted of all teachers in llorin city, which was estimated at 1,568 (Kwara State Universal Basic Education Board, 2018). However, the target population consisted of teachers in selected primary schools in Ilorin City. Ilorin, as a state capital, is a cosmopolitan city characterized by activities that could predispose children to inattention (the context of this study). Thus, 10\% (156.8) of the study's population was adopted, which was approximated to 160 . Therefore, 160 teachers directly engaged in teaching at the basic level of education that purposively selected across 10 schools within llorin city. The schools that were selected on purpose are located in the central part of llorin due to its characteristics by different activities that could potentially predispose children to inattention. The participants were stratified across the variables of gender, qualifications, and work experience.

\section{Research Instrument}

Based on the literature review, the instrument used was a questionnaire designed by the researchers and titled "Assessment of Inattentive Behaviour Questionnaire (AIBQ)". It has two sections; A and B. Section "A" contained Bio-Data information of respondents (gender, qualification, and work experience), while "B" consists of 15 items which elicited information on the students' inattentive behavior. The response to the 15 items used a four-point Likert type of Strongly Agree (4); Agree (3); Disagree (2); Strongly Disagree (1). The content validity of the instrument was established by five senior lecturers in the fields of Measurement and 
Evaluation and Counsellor Education, University of Ilorin, Nigeria. The test-retest method was used to establish reliability through Pearson's Moment Correlation Coefficient formula. A value of $r=0.81$ was obtained, which was considered adequate. This conclusion is in line with the previous study, which showed that the correlation coefficient between 0.50-1.00 had a high correlation, and it was suitable for a research purpose (Thomas, 2003).

\section{Data Collection}

The questionnaire forms were administered on the participants by the researcher after obtaining the informed consent to voluntarily respond to the items contained in the instrument. All the 160 questionnaire forms were successfully retrieved after completion.

Since the research adopted a four-point Likert scale format for the research instrument, which is on a continuum of 4-1. The highest and lowest scores for each item are either 4 or 1 as the case may be. The highest mean summation is 60 (15X4), while the lowest is 15 (15X1) because the questionnaire has 15 items. The determining point is the average mean score $\left(\sum X / 15\right)$. Hence, if the value (average) is 2.50 and above, it indicates that classroom inattentive behavior is high among basic school pupils but, if otherwise (below 2.50), it implies the behavior is low, as assessed by the teacher. When the four-point rating scale is adopted, a mean score of 2.5 is appropriate as the decision point in the research (McLeod, 2019).

After collecting the data, frequency counts, a statistical method of means, the standard of means, standard deviation, t-test, and ANOVA were used in the data analysis. The t-test and ANOVA sought to find the difference between means of two or more variables. All hypotheses will be tested at the 0.05 alpha level.

\section{RESULTS}

Table 1. Distribution of Participants by Gender, Qualification and Work Experience

\begin{tabular}{lcc}
\hline Variable & Frequency & $\%$ \\
\hline Gender & 62 & 38.75 \\
Male & 98 & 61.25 \\
Female & 160 & 100.0 \\
Total & & \\
Qualification & 38 & 23.75 \\
NCE & 118 & 73.75 \\
First Degree & 4 & 2.05 \\
Postgraduate & 160 & 100.0 \\
Total & & \\
Work Experience & 107 & 66.88 \\
10 years and below & 53 & 33.12 \\
Above 10 years & 160 & 100.0 \\
Total &
\end{tabular}


Table 1 shows that more female (61.25\%) and teachers with 10 years and below work experience (66.88\%) participated in the research, while most teachers with First Degree qualification participated compared with those with NCE and postgraduate. This indicated that female teachers, which had First Degree and 10 years and below work experience, usually had a higher population above other groups of teachers in the primary schools in llorin city.

Research Question: What is the level of attentive classroom behavior of basic school pupils?

Table 2. Mean score on the assessment of inattentive classroom behavior among primary school students

\begin{tabular}{lc}
\hline During classroom instruction, pupils: & $\bar{X}$ \\
\hline Exhibit fidgeting & 3.61 \\
Get distracted quickly & 3.52 \\
Find it difficult to pay close attention & 3.55 \\
Show an inability to remain seated & 3.51 \\
Engage in frequent intrusion on others & 3.48 \\
Move around when not required & 3.47 \\
Often avoid tasks that require prolonged thought & 3.42 \\
Create excessive noise & 3.40 \\
Exhibit difficulty on time management & 3.33 \\
Often make careless mistakes & 3.25 \\
Appear not listening to the teacher & 3.11 \\
Often forget to complete tasks & 3.04 \\
Find it difficult following assignment & 2.98 \\
Often fixate on nothing in particular & 2.91 \\
& Average Mean $=$ \\
& 50.18 \\
\hline
\end{tabular}

Table 2 shows that the average mean (3.35) was above 2.50, which was the determining point for the level of inattentive classroom behavior among students. This implies that teachers assessed that the students had high inattention classroom behavior.

Hypothesis 1: There is no significant difference in teachers' assessment of inattentive classroom behaviour among primary school students based on gender.

Table 3. The result of the t-test showing based on gender

\begin{tabular}{|c|c|c|c|c|c|c|c|}
\hline Gender & $\mathbf{N}$ & $\bar{X}$ & SD & df & Cal t. & Crit t. & p.val \\
\hline Male & 62 & 52.84 & 6.41 & \multirow{2}{*}{158} & \multirow{2}{*}{1.88} & \multirow{2}{*}{1.96} & \multirow{2}{*}{0.14} \\
\hline Female & 98 & 53.01 & 5.73 & & & & \\
\hline
\end{tabular}


hypothesis was accepted. Thus both male and female participants (teachers) were similar in the assessment of inattentive classroom behavior among basic school students.

Hypothesis 2: There is no significant difference in teachers' assessment of inattentive classroom behaviour among primary school students based on qualification.

Table 4. Analysis of Variance (ANOVA) result based on qualification

\begin{tabular}{lcclccc}
\hline Source & SS & df & MS & Cal. F & Crit. F & p.val \\
\hline Between Groups & 82.352 & 2 & 41.176 & 2.15 & 3.00 & 0.11 \\
Within Groups & 3715.091 & 157 & 23.663 & & & \\
Total & 3797.443 & 159 & & & & \\
\hline
\end{tabular}

Table 4 shows that the cal-F(2.15) was less than the crit-F(3.00) with a corresponding p.value (0.11) greater than the level of significance (0.05). The hypothesis was accepted. Thus, there was no significant difference in teachers' assessment of inattentive classroom behavior among primary school students based on qualification. It implies that regardless of qualification, the respondents were similar in their assessment of inattentive classroom behavior among primary school students.

Hypothesis 3: There is no significant difference in teachers' assessment of inattentive classroom behaviour among primary school students based on work experience.

Table 5. The result of t-test based on the work experience of the respondents

\begin{tabular}{|c|c|c|c|c|c|c|c|}
\hline Work Experience & $\mathbf{n}$ & $\bar{X}$ & SD & df & Cal.t & Crit.t & p.val \\
\hline 10 years and below & 107 & 50.72 & 4.55 & & & & \\
\hline Above 10years & 53 & 53.68 & 2.17 & 158 & 2.77 & .1 .96 & ${ }^{*} 0.01$ \\
\hline
\end{tabular}

$*$ Sig $=p>0.05$

The result shows that the cal- $+(2.77)$ was greater than the crit- $t(1.96)$ with the corresponding p.value $(0.01)$ less than the level of significance (0.05). Therefore, the hypothesis was rejected. Thus, there was a significant difference in teachers' assessment of inattentive classroom behavior among primary school students based on work experience. This implies that teachers with 10 years and above work experience displayed higher expression with a mean of 53.68 against 50.72 (10 years and below).

\section{DISCUSSION}

The findings revealed that inattentive classroom behavior was significantly high among primary school students. This is in line with the previous research in which attention-deficit is defined as one of the most commonly diagnosed behavioral problems in the U.S. classrooms, particularly among elementary (basic) school children (Handelman, 2011). In addition, there is research revealed that teachers rated high attention deficit among primary school students 
compared with older upper-grade students in the US (Willcutt, 2012). Moreover, attention deficit also significantly occurred among students in Southern Nigeria (Alikor et al., 2015).

The high level of inattentive classroom behavior among primary school students could be a reflection at their stage of development, which is often characterized by inattention, hyperactivity, and playfulness. The most prominent features of inattentive classroom behavior among primary school students as assessed by teachers in this research included having difficulty in focusing and paying close attention, fidgeting, and getting distracted quickly. All these features would become a limitation to classroom instruction and learning in school. The results are in line with the previous research results, which revealed that the common features of students' inattention include having difficulty in paying close attention to a task, making careless mistakes, having difficulty in focusing on activities or tasks, becoming distracted easily, finding it difficult to play or engage in activities without creating excessive noise, and having difficulties with following instructions to complete tasks (Nall, 2018).

The results revealed that there was no significant difference between male and female teachers in their assessment of inattentive classroom behavior among primary school students. This indicated that both male and female teachers are similar in their assessment of students' inattentive classroom behavior. This is in line with the research results, which showed that respondents were similar in their expression on attention deficit hyperactivity disorder among students in Port-Harcourt, Nigeria (Alikor et al., 2015). This implies that regardless of gender, teachers would report a similar assessment of students' inattentiveness in the classroom. Many people argue that gender is not always likely to play a significant role in the perception, expression, or assessment of inattentive classroom behavior by teachers because students express their inattentive behavior in the presence of teachers without reservation for gender.

There was no significant difference in the assessment of inattentive classroom behavior among primary school students based on qualification. This suggests that regardless of the difference in the educational qualification, teachers presented a similar assessment of inattentive classroom behavior among primary school students, Since teachers' qualification regulated students' inattentive behavior, it could be a reflection of developmental challenges of children. Therefore, teachers are likely to often find a similar degree of students' inattentive behavior. This implies that educational qualification would not play a significant role in teachers' assessment of inattentive classroom behavior among students. This is in line with the previous research, which found similar responses on knowledge of ADHD among the students by the teachers in Lagos State, Nigeria based on the level of education (Jimoh, 2014). 
There was a difference in teachers' assessment of inattentive classroom behavior among primary school students based on work experience. This implies that teachers would not often be similar in the assessment of students' inattentive behavior because of varying degrees of work experience. The research revealed that respondents with work experience above 10 years showed a higher result in the assessment of inattentive classroom behavior among students. These results may be considered right because the longer a person has taught, the more likely he or she will be able to assess different behavioral problems (such as inattention) among students. The result is in line with the findings in the previous research, which revealed that the respondents who had a long job experience suggested more solutions to attentiondeficit/hyperactivity disorder (Willcutt, 2012). Therefore, work experience would often play a significant role in the assessment of inattentive classroom behavior among students.

\section{CONCLUSION}

Based on the research findings, the conclusion is that the teachers assessed high inattentive classroom behavior among primary school. In addition, the most common characteristics of inattentive behavior among students were fidgeting, becoming distracted easily, and having difficulty in paying close attention and remaining seated. Thus, students' inattentive behavior could be a major constraint in the teaching and learning process in the classroom. Therefore, attention is required to curtail the trend and enhance smooth classroom instruction. Teachers were similar in their assessment of inattentive classroom behavior among students based on gender, qualification but not based on work experience.

\section{RECOMMENDATION}

Moreover, there is some recommendation for several parties, for instances

- Early childhood education teachers and guidance counsellors should synergize to develop strategies for reducing inattentive classroom behaviour among primary school students;

- Counsellors should work closely with the school management team to provide an environment that would reduce inattention among basic/primary school students;

- Primary school Teachers should directly engage in applying dynamic teaching methods that could help to sustain attention among students;

- Primary school teachers with longer work experience should be engaged to provide enlightenment for their counterparts with lower work experience on inattentive classroom behaviour among students.

\section{REFERENCES}

Adesola, S. A., \& Asifatu, S. A. (2013). Educational Implication of Attention Deficit 
Hyperactivities Disorder Students at F.C.E. ( SP.) Oyo . 2(7), 141-146. https://doi.org/10.5901/ajis.2013.v2n7p141

Alikor, E. A. D., Frank-Briggs, A. I., \& Okoh, B. A. N. (2015). Attention Deficit Hyperactivity Disorder Among School Children in Port Harcourt, Nigeria. American Journal of Psychiatry and Neuroscience, 3(2), 23. https://doi.org/10.11648/j.ajpn.20150302.12

Egbochuku, E. O., \& Abikwi, M. I. (2007). The Prevalence of Attention Deficit/Hyperactivity Disorder (ADHD) among Primary School Pupils of Benin Metropolis, Nigeria. Journal of Human Ecology, 22(4), 317-322. https://doi.org/10.1080/09709274.2007.11906041

Gutcheck. (2020). What Is Descriptive Research?. Retrieved 20 January 2020 from https://www.gutcheckit.com/blog/what-is-descriptive-research/

Handelman, K. (2011). Attention Difference Disorder: How to Turn Your ADHD Child or Teen's Differences into Strengths in 7 Simple Steps. Morgan James Publishing.

Jimoh, M. (2014). Knowledge and Attitudes towards Attention Deficit Hyperactivity Disorder among Primary School Teachers in Lagos State, Nigeria. 23, 7-16.

Kwara State Universal Basic Education Board. (2018). Annual School Report.

Lundervold, A., Bøe, T., \& Lundervold, A. (2017). Inattention in primary school is not good for your future school achievement-A pattern classification study. PLOS ONE, 12, 1-15. https://doi.org/10.1371/journal.pone.0188310

McLeod, S. (2019). Likert Scale Definition, Examples and Analysis. Retrieved 5 February 2020 from http://www.simplypsychology.org/likert-scale.html

Merrell, C. (2017). Inattentive behaviour in the classroom. Retrieved 30 January 2020 from https://www.cem.org/blog/inattentive-behaviour-in-the-classroom/

Nall, R. (2018). What to know about ADHD. Retrieved 30 January 2020 from https://www.medicalnewstoday.com/articles/323667

Nigerian Educational Research and Development Council (NERDC). (2013). Federal Republic of Nigeria National Policy on Education 2013 (p. 56).

Rodriguez, A. (2017). Inattentiveness Affects Later Academic Performance of Children With ADHD. Retrieved 25 January 2020 from https://www.ajmc.com/view/inattentivenessaffects-later-academic-performance-of-children-with-adhd

Smith, M., Robinson, L., \& Segal, J. (2019). ADHD in Children. Retrieved 20 January 2020 from https://www.helpguide.org/articles/add-adhd/attention-deficit-disorder-adhd-inchildren.htm 
Stöppler, M. C. (2010). Inattention: Symptoms \& Signs. Retrieved 20 January 2020 from https://www.medicinenet.com/inattention/symptoms.htm

Thomas, R. (2003). Blending Qualitative \&amp; Quantitative Research Methods in Theses and Dissertations. SAGE Publications, Inc. https://doi.org/10.4135/9781412983525

Uwe, E. (2000). Early identification and management strategies of attention deficit/hyperactive disorder in children: The Exceptional Child. The Exceptional Child, $4(1), 26-35$.

Willcutt, E. G. (2012). The prevalence of DSM-IV attention-deficit/hyperactivity disorder: a meta-analytic review. Neurotherapeutics : The Journal of the American Society for Experimental NeuroTherapeutics, 9(3), 490-499. https://doi.org/10.1007/s13311-012-01358 